\title{
Research on the Choice Strategy of Rural Mutual Assistance Pension Model -- Based on the Investigation of Y City
}

\author{
Chen Siyu ${ }^{1, a}$, Luo zirui ${ }^{2, b}$, Duan Shanjie ${ }^{3, c}$
}

\begin{abstract}
${ }^{I}$ Department of Social Work, Sichuan Agricultural University, Yucheng, Ya 'an, Sichuan, China
${ }^{2}$ Department of Social Work, Sichuan Agricultural University, Yucheng, Ya 'an, Sichuan, China

${ }^{3}$ Department of Social Work, Sichuan Agricultural University, Yucheng, Ya 'an, Sichuan, China

1179162440@qq.com

b1257412481@qq.com

c1315682830@qq.com
\end{abstract}

\begin{abstract}
As the rural pension problem becomes more and more serious, mutual support for the elderly emerged as a way of supporting the elderly emerged. The typical models of mutual aid for the aged are time bank, mutual aid happy home and Yi Zhuang. The time bank model is based on the exchange of services, the mutual help happiness institute model is based on the common life and cooperation, and the Yi Zhuang model is based on the exchange of social capital. Compared with other models, the model of mutual aid happiness Courtyard has sufficient material foundation, spiritual tradition fit, and the overall model has higher embedding degree.
\end{abstract}

Keywords: Mutual support for the aged, mode selection, rural elderly

\section{农村互助养老模式的选择策略研究一一基于对 Y 市的 调研}

陈思雨 $^{1,}$, 罗紫瑞 ${ }^{2, ~ b}$, 段善杰 ${ }^{3, c}$

${ }^{1}$ 四川农业大学社会工作系, 雨城, 雅安, 四川, 中国

${ }^{2}$ 四川农业大学社会工作系, 雨城, 雅安, 四川, 中国

${ }^{3}$ 四川农业大学社会工作系, 雨城, 雅安, 四川, 中国

a1179162440@qq.com

b1257412481@qq.com

c1315682830@qq.com

\section{摘要}

随着农村养老问题日趋严重, 互助养老方式应运而生。互助养老方式的典型模式为时间银行模式、互助幸福院 模式、义庄模式。时间银行模式是基于服务的互相交换，互助幸福院模式是基于共同生活与协作，义庄模式是 基于社会资本的交换。较之其他模式，互助幸福院模式物质基础充足，精神传统契合，整体模式嵌入度更高。

关键词: 互助养老 模式选择 农村老年人

\section{1. 问题的提出}

21 世纪是人口老龄化的时代。第七次全国人口
普查数据显示, 2022 年我国 60 岁及以上的人口数量 为 26401 万人, 占 $18.70 \%$, 其中 65 岁及以上人口为 19064 万人，占 $13.50 \%{ }^{[1]}$ 。我国人口老龄化程度进一 
步加深。按照目前的趋势判断, 中国将在 “十四五” 期间进入中度老龄化阶段, 2035 年前后进入重度老 龄化阶段 ${ }^{[2]}$ 。这使得如何应对不断加剧的老龄化趋势, 成为了经济社会发展的一个新的命题。在这之中, 农 村养老面临着更为巨大的挑战。全国乡村 60 岁、65 岁及以上老人的比重分别为 $23.81 \% 、 17.72 \%$, 比城 镇分别高出 $7.99 、 6.61$ 个百分点 ${ }^{[1]}$, 农村老年人口 比重不断扩大, 未富先老, 大量的养老问题亟待解决。 而传统的两大养老模式在农村也面临着发展困境。首 先由于城镇化加速, 大量青壮年迁移进城市, 农村家 庭养老功能衰退。与此同时, 农村养老服务同样缺口 巨大。以村委会数量为基数进行估算, 注册登记的养 老机构、社区养老照料机构和设施、社区养老设施的 覆盖率只有 $6.4 \%$ 、12\%和 $19 \%$, 农村土壤中难以孕 育出机构养老这一市场化逻辑下的养老模式。农村养 老面临着巨大的资源与服务上的困境, 已经成为我国 的养老事业的重大现实挑战。

\section{2. 文献回顾}

老龄化是现阶段我国面临的重大社会问题, 在城 镇加速发展的背景下, 农村大量青壮年劳动力流失, 农村 “空巢化”严重, 农村地区的养老问题更加突出, 而传统的养老模式面临各种困境。在家庭养老层面, 由于农村代际关系的变迁, 打破了多代共居模式, 造 成了子女对父母的赡养缺失; 在福利养老层面, 农村 经济发展滞后, 政府财政投入有限, 农村老年人无法 依靠政府福利养老; 在机构养老层面, 农村老年人经 济收入低, 以营利为目的的市场资本不愿向农村投入 资金。除此之外，传统养老模式聚焦于家庭、政府等 主体在养老模式中的主责, 而忽略了老年人本身的经 验、资源等优势。如若在资源相对贯乏的农村地区采 取以上模式, 会造成老年人的自身优势无法展现、而 其外部支持不足的尴尤局面。在家庭养老弱化、社会 养老不足、政府养老有限的情况下, 急需一种结合农 村发展情况、满足农村老人需求的养老模式, 即互助 养老模式。

关于互助养老, 聂建亮等学者认为 “互助养老是 在城镇化快速发展背景下, 应对农村家庭养老功能持 续弱化, 以及弥补当前农村养老服务供给失效与不足 的重要养老模式” “4]; 刘妮娜认为互助养老是 “充分 利用老年人力资源, 推动老年人之间的自助一互助” ${ }^{[5]}$ 。基于众多研究理论, 笔者将农村互助养老解释为 在农村资源有限的情况下, 通过 “互助” 的形式充分 利用农村资源, 激发农村老年人主动性的一种补充性 养老模式。如今互助养老模式已形成 “时间银行” “互 助幸福院” “老伙伴” “义庄” “社区互助” 等多种模 式, 但互助养老模式还存在资源整合有限性不高, 组 织规范化不足, 受益面有限等诸多问题 ${ }^{[6]}$ 。

\section{3. 三种互助养老模式的基本内容}

互助养老模式在欧美发达国家建立了比较成熟
的制度。但互助养老模式作为一种舶来品, 在九十年 代才被引入中国, 尚未建立起一套较成熟且可大范围 复制推广的模式体系。因此, 笔者选取十几种互助养 老模式中最具代表性的三种模式进行介绍。

\section{1 时间银行模式}

时间银行模式通常指低龄健康老年人服务高龄 老年人, 赚取服务时长, 用于自己将来需要养老服务 时换取等量时长的服务, 服务内容包括生活照料、医 疗照护等。也有更为广义的说法是时间银行的参与者 可以不同年龄段的居民，不局限于老年人。在时间银 行中, “时间” 是一个重要因素, 它被赋予 “货币” 的意义, 作为一种等价物衡量服务价值, 并且可以进 行流通交换。从参与对象来说, 时间银行的参与者包 括管理者（政府、社区或社会组织）、志愿者、服务 对象, 遵循自愿进出、互惠互助原则。志愿者与服务 对象双方在管理组织协调下提供服务、满足需求，权 利与义务对等。时间银行的资金来源则为多方支持, 如政府资助、组织会员缴纳会费等。上海经验中的“老 年生活护理互助会” 是时间银行运行的典型案例。该 互助会在 1998 年由上海市老龄委试点成立, 采取“劳 务储存” 兼 “货币储存” 两种储存方式。会员缴纳会 费兼提供志愿服务, 满十五年后便可获得由互助会提 供的相应资助与服务 ${ }^{[7]}$ 。时间银行模式减轻社区养老 压力, 发挥低龄老年人的优势, 增加高龄老年人的社 区参与，实现了管理者、志愿者、服务对象的多方共 赢。对于社区而言, 能充分利用社区资本满足养老需 求, 促进和谐社区建设; 对于志愿服务者而言, 能提 升自我效能感，同时储备养老资本; 对于服务对象而 言, 能提高社会参与, 满足其物质精神需求。但时间 银行在我国仍是舶来的新模式, 存在社区志愿者招募 难、服务延期兑换风险大、资金来源不稳定、老年人 参与积极性不高等诸多问题, 想要大范围推广就必须 建立统一的组织管理制度与兄换服务的信息平台。

\section{2 互助幸福院模式}

“互助幸福院” 农村互助养老模式起源于 2008 年的河北省肥乡县, 之后在政府的大力推广下在广大 农村地区试点运行。具体而言, 互助幸福院是在各级 政府主导下，村委、社会组织、村集体等多元主体按 照 “集体筹一点、个人掏一点、政府补一点、社会捐 一点” 的办法共同筹措资金, 利用闲置房屋资源建设 场地, 安置村中老年村民集体居住的养老组织, 集文 化娱乐、生活照料、教育咨询、医疗服务等功能于一 身。建成之后, 互助幸福院的运营由院内老年人选举 委员会进行管理, 村委指导监督, 社会组织提供专业 技术人员进行协助。准入制度上, 互助幸福院采取自 愿出入的原则, 在与老人及其子女进行协商, 签订协 议后便可入院。入院后的日常活动开展分为两类。文 化娱乐、餐饮、住宿等非专业活动由老年人自主开展。 医疗保健、咨询教育等专业领域则由幸福院聘请专业 人员开展。与传统机构养老相比, 互助养老院由政府 
补贴, 老年人仅需支付日常运营的小额开销, 入住费 用低; 在自己居住的村落中就能享受配套服务, 避免 离家里村, 实现 “就地养老”。互助幸福院在个人层 面上使得老年人由需求者转变为服务提供者, 有效满 足农村老年人的衣食住用娱的需求，提升农村老年人 人的自我价值感，构建社会支持网络; 社区层面上延 续农村“守望相助”的传统文化观念, 增进邻里关系, 促进新农村建设。由上至下的管理体制也为互助幸福 院带来行政压迫，进而带来自主性不高、形式化等问 题。在老年人群体保障的完整性上, 互助幸福院也无 法吸纳残疾、卧病在床的老年人群体, 需要其他院外 服务补充。

\section{3 义庄模式}

义庄是古代家族养老的主要载体。义庄的运营模 式基于我国传统的宗法制与封建传统。义庄中家族富 人为捐赠者, 为族内捐赠 “义田” 以满足族内修建祠 堂、祭祀、兴办学堂、赡养老人等公共事务的需求, 换取社会声望与认可, 加强其以宗族为载体获取资源 的合法性。我国古代义田按捐献者身份的不同可分为 官捐义田、民捐义田、商捐义田、诸生捐义田四类 ${ }^{[8]}$ 。 捐赠者付出经济资本, 换取声望等社会资源, 受赠者 获取经济利益, 整个家族的凝聚力和整体实力进而得 到增强。在土地革命之后, 族田纷纷从富农手上转移 到无地农民手中, 传统的义田模式随之消亡。义庄养 老模式被家庭养老、社会养老、机构养老、自我养老 等现代养老模式取代。但在现在农村养老供求矛盾突 出, 家庭养老功能弱化的现在, 我国古代的义庄养 老模式仍具有现实意义。现阶段农村仍以聚族而居为 主要形态, 费孝通先生所说的 “乡土社会” 在农村犹 存, 义庄养老模式仍有延续发展的现实基础。我们可 以用 NGO 的形式来代替义庄, 发展现代新型的家族 邻里互助养老, 以充分培育和激活乡土社会中的社 会资本, 为农村养老事业服务 ${ }^{[8]}$ 。现在的义庄模式还 处在刚刚起步阶段, 仅在少数地区试点运行, 但可以 预见其未来的发展潜力是巨大的。

\section{4. 农村的互助养老模式选择一一以 $Y$ 市为例}

\section{1 三种模式的内涵解析}

\section{1.1 时间银行模式}

以“老年生活护理委员会”为例的时间银行模式, 本质上是基于市场逻辑下的服务交换。低龄健康老年 人服务高龄老年人，换取 “时间货币”，用于自己将 来需要养老服务时换取等量时长的服务, 这一行为实 质上是低龄老年人在为未来提供养老的资本积累。交 换服务这一决定也是老年人基于个人因素进行考量。 在公民社会中, 时间银行以一种延迟满足的契约形式 运行, 以政府的公信力、契约精神为基础, 构建了社 区中老年人进行服务互助的一种互助养老模式, 体现 了代际之间的劳动交换与转移, 能有效缓解政府与家
庭的养老压力。

\section{1.2 互助幸福院模式}

互助幸福院模式本质是上乡土社会中老年人的 协作互助, 共同生活。互助幸福院模式起源于农村地 区，以农村地区的 “守望互助” 精神为文化基础，熟 人社会中个体之间的情感联结为纽带。在农村地区的 村落中建设一个老年人协作生活的空间院落。在幸福 院这个共同空间之中老年人共同进行文化娱乐、饮食 起居、生活照料等活动的互助, 进而进行情感与精神 上的互动。与时间银行模式相比, 互助幸福院模式中 的共同生活的老年人更多了一种情感上的连接。因此, 互助幸福院模式更为契合农村熟人社会的现实基础, 为养老服务较为荒芜的农村地区提供了一种因地制 宜的就地养老模式。

\subsection{3 义庄模式}

义庄模式本质上是一种社会资本的相互交换。传 统封建社会中捐赠者以 “义田” 这一经济资本交换了 社会认可、地位与声望, 进而利用自身更为稳固的物 质、社会资本获取更多资源, 以稳固与提升自己在宗 族中的地位。在这之中, 受赠者获得了经济资本, 同 时宗族整体在紧密连接、盘根错节的资本的交换过程 中更加亲密, 整体实力也有所增加。现代社会的义庄 模式虽然把 “宗族” 换成 “村落” 或 “社区”, “义 田”换成 “物资”，但其本质上仍然是依托社会资本 的互换建立起来的互助体系。

\section{2 互助幸福院的模式选择}

\subsection{1 物质基础充足}

在物质成本的考量上, 互助幸福院模式建立初期 需要的资金主要由政府出资，村民出资少，院落建设 选址也是根据农村闲置房屋的翻新修建或闲置土地 资源的再利用而来, 而其中需要的劳动力资源主要由 村落老年人提供, 建设所需物质成本极低。运营期间, 则由老年人自行建立管理规范制度, 村委会与社会组 织只需要从旁指导与协助即可, 运营成本仅仅只是老 年人共同生活所需的米面粮油等基础物资, 开销金额 不大。以 Y 市为例, 笔者调研的几个村落之中都有大 量的荒地与闲置屋舍, 老年人每日耕种劳动量不重, 闲暇时光多，且很有翻修房屋的经验。故而从物质基 础的角度考量, 互助幸福院模式运行成本更低。

\section{2.2 精神传统契合}

当整个社会从有机团结迈向机械团结的关系之 中, 中国乡村的改变进程仍然是较为缓慢的, 关系与 人际在中国传统乡村中仍然盛行, 费孝通先生把乡土 社会描述为 “熟人社会” 与 “差序格局”。这种传统 的 “守望相助” 互助思想体现在养老方面就形成了农 
村老年人之间普遍的互尊互敬、互助合作的精神。而 互助幸福院模式中老年人共同生活, 其运作的核心条 件之一便是要求生活在其中的老年人相互协作, 这与 中国传统乡村的精神内核是相互契合的。并且进一步 来说, 乡村老年人之间的互助精神能够在这种连结模 式中得到进一部的发展。如笔者调研的的 $\mathrm{Y}$ 市 $\mathrm{C}$ 村之 中, 老年人普遍在村落中居住了 20 年以上, 彼此之 间相互熟识, 在大事小事上互相帮助。这种情感的紧 密连结与共同的文化环境使得互助幸福院的协作生 活模式具备情感与文化基础。

\subsection{3 整体模式嵌入}

互助幸福院模式虽然非常强调老年人之间的融 洽和合作行为, 但是其本质上仍然无法逃离院舍化的 运作逻辑。而在中国乡村所普遍存在的村委会-村支 委行政体系能够非常顺畅的与互助幸福院模式相结 合, 在管理主体与运作机制上两者具有天然的契合。 从推行模式来看, 互助幸福院模式由政府至上而下推 行, 建设与日常管理都有政府颁布的比较详尽的制度 文件规范, 处在政府的管理体系之中。同时, 幸福院 所选举的管理委员会的权力也仅仅体系在养老院内 部的日常运营与执行政策, 与村委会-村支委体系没 有权力的明显冲突, 能够毫无阻碍地嵌入村委会村支委行政体系之中。

\section{5. 结论}

农村养老面临服务与资源的双重困境。农村互助 养老在农村资源有限的情况下, 通过 “互助” 的形式 充分利用农村资源, 激发农村老年人主动性, 是解决 农村养老资源服务困境燃眉之急的一种行之有效的 养老方式。互助养老方式的典型模式中, 时间银行模 式是基于服务的互相交换, 互助幸福院模式是基于共 同生活与协作，义庄模式是基于社会资本的交换。较 之其他模式, 互助幸福院模式物质基础充足, 精神传 统契合, 整体模式嵌入度更高, 能够作为农村养老的 一种补充性模式。

\section{REFERENCES}

[1] National Bureau of Statistics. (2020) The Seventh National Census Bulletin. http://www.stats.gov.cn/tjjj/tjgb/rkpcgb/qgrkpcgb/2 02106/t20210628_1818824.html

[2] Xinhua News Agency. (2021) Decision of the CPC Central Committee and The State Council on Optimizing birth Policy to Promote long-term Balanced Development of Population. http://www.xinhuanet.com/politics/2021-07/20/c_1 127675462.htm

[3] Liu, L. (2021) Challenges and tasks of improving rural old-age service system during the 14th Five-year Plan period. Administrative Reform, 79-
87.

[4] Nie, J. Sun, Z. Wu Y. (2021). Social Security Research, 22-33.

[5] Liu, N. (2017) Mutual assistance and Cooperation: Research on mutual assistance social pension model in Rural China [J]. Population research, 41:72-81.

[6] Wu, C. (2021) Wu Han. How to deal with the old people's mutual help in rural areas in the new era? [J]. Journal of Central China Normal University (Humanities and Social Sciences edition), 60:12-20.

[7] Jing, J. Zhao, R. (2015) Mutual care for the aged: inspiration from "love time bank" [J]. Ideological front, 41:72-77.

[8] Yuan, T. (2009)"Yi Zhuang": An important reference for the establishment of modern rural family neighborhood mutual support pension model -based on the perspective of social capital [J]. Theoretical Guide, 19-21. 